\title{
Fabrication of Copper Hydroxyphosphate with Complex
}

\section{Architectures}

\author{
Jiasheng Xu and Dongfeng Xue*
}

State Key Laboratory of Fine Chemicals, Department of Materials Science and Chemical Engineering, School of Chemical Engineering, Dalian University of Technology, 158 Zhongshan Road, Dalian 116012, P. R. China

*Corresponding author. E-mail: dfxue@chem.dlut.edu.cn

\section{Supporting Information}



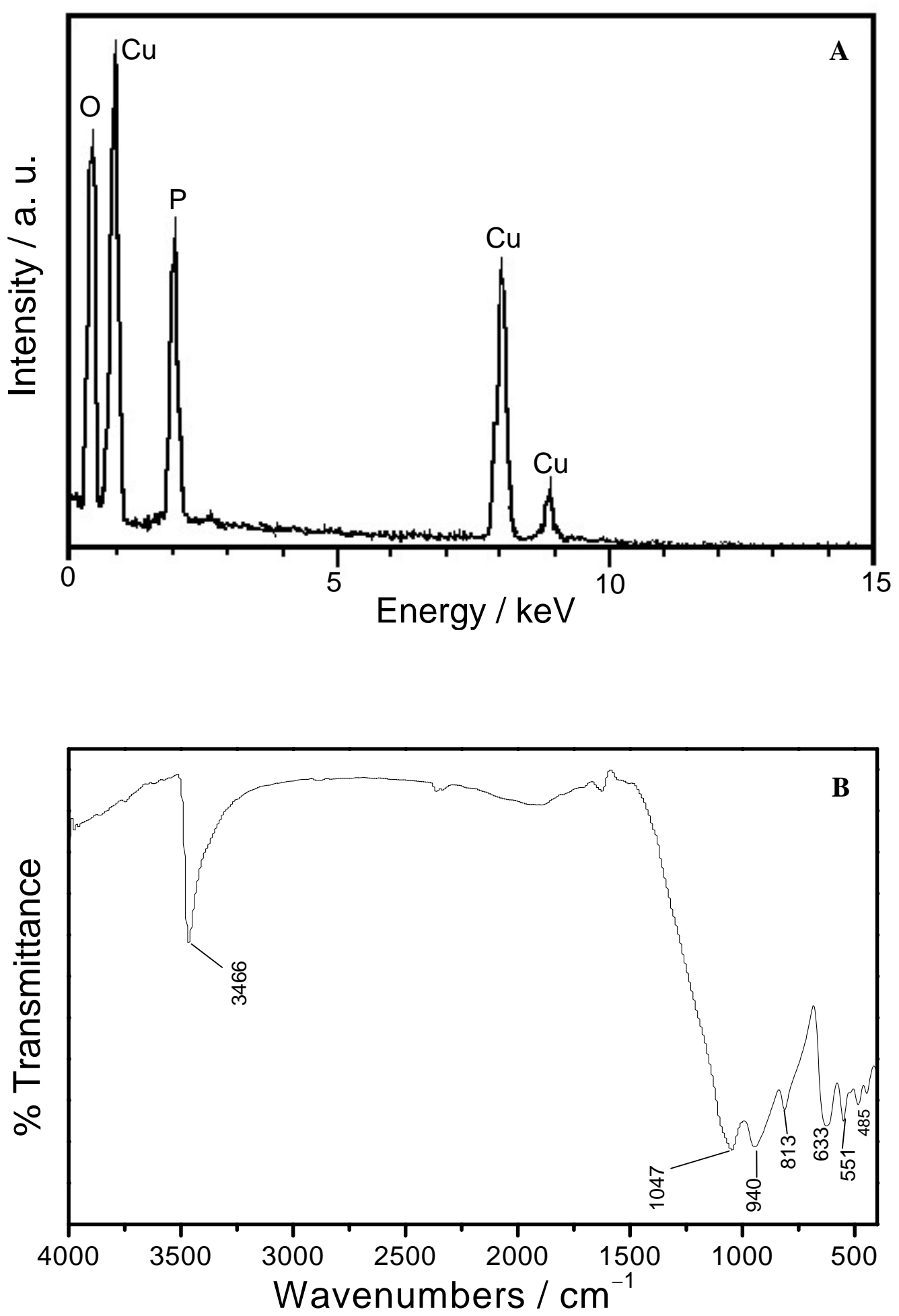

Figure S1. (A) Energy-dispersive X-ray spectra of sample $\mathrm{Cu}_{2}(\mathrm{OH}) \mathrm{PO}_{4}$. (B) FT-IR spectra of sample $\mathrm{Cu}_{2}(\mathrm{OH}) \mathrm{PO}_{4}$, which coincide well with those reported results in the Ref [18a]. 


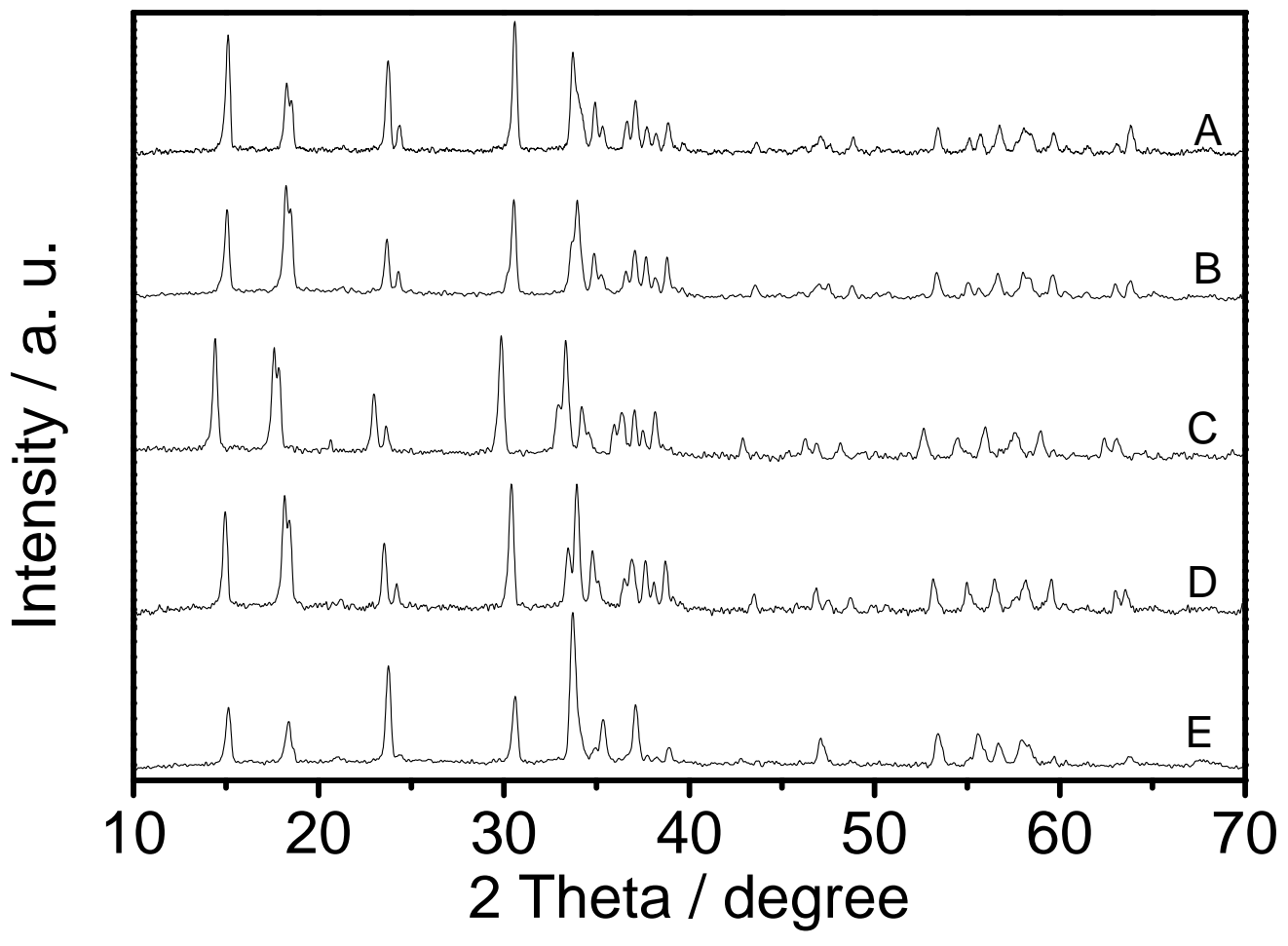

Figure S2. Representative XRD patterns of $\mathrm{Cu}_{2}(\mathrm{OH}) \mathrm{PO}_{4}$ architectures. Experimental conditions: A, B, C, D, and E correspond to Nos 3, 4, 5, 6, and 7 in Table 1, respectively. By the way, the standard diffraction pattern of $\mathrm{Cu}_{2}(\mathrm{OH}) \mathrm{PO}_{4}$ (JCPDS No. 36-0404) has been shown as a reference in Figure 1. 


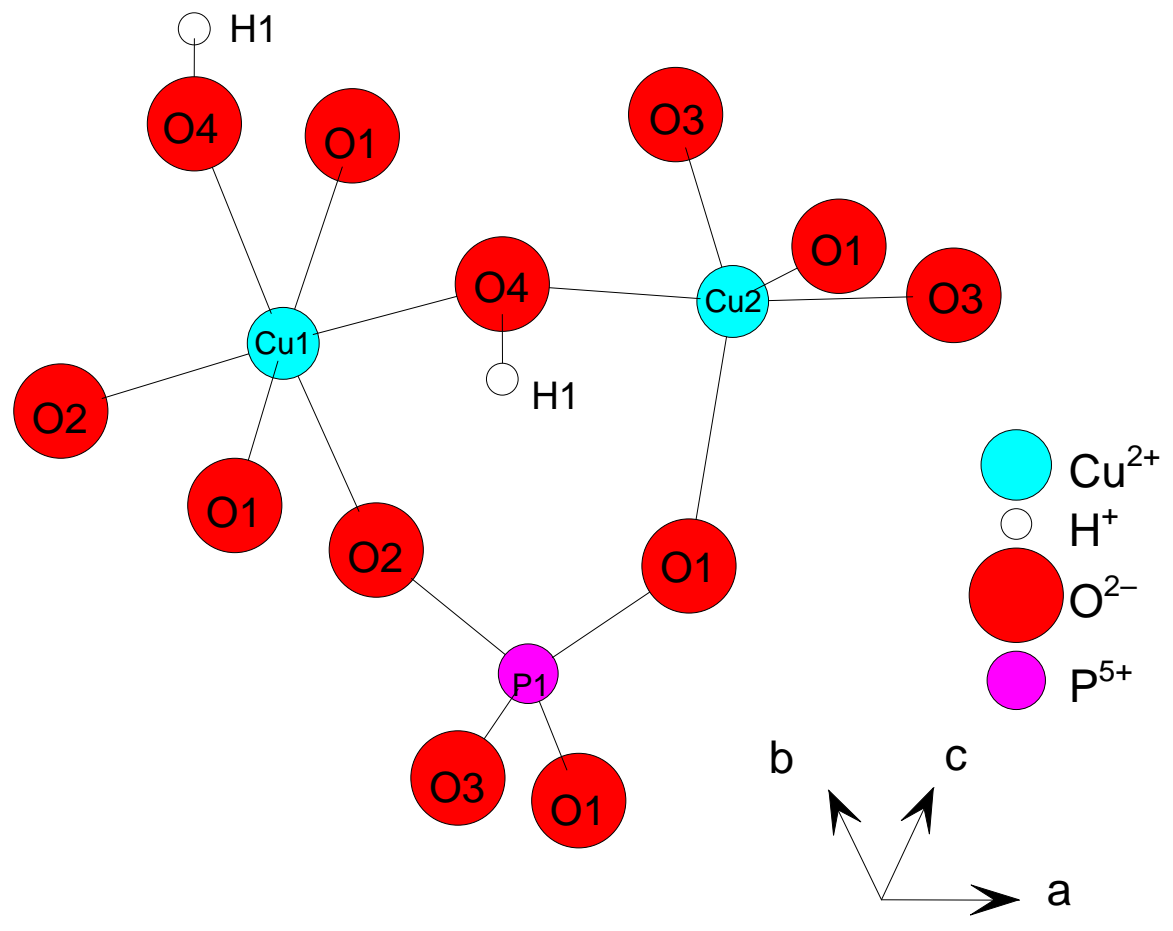

Figure S3. Part of the crystal structure of copper hydroxyphosphate $\left[\mathrm{Cu}_{2}(\mathrm{OH}) \mathrm{PO}_{4}\right]$, which consists of both $50 \%$ 5-coordinated $\mathrm{Cu}$ and $50 \%$ 6-coordinated $\mathrm{Cu}$.

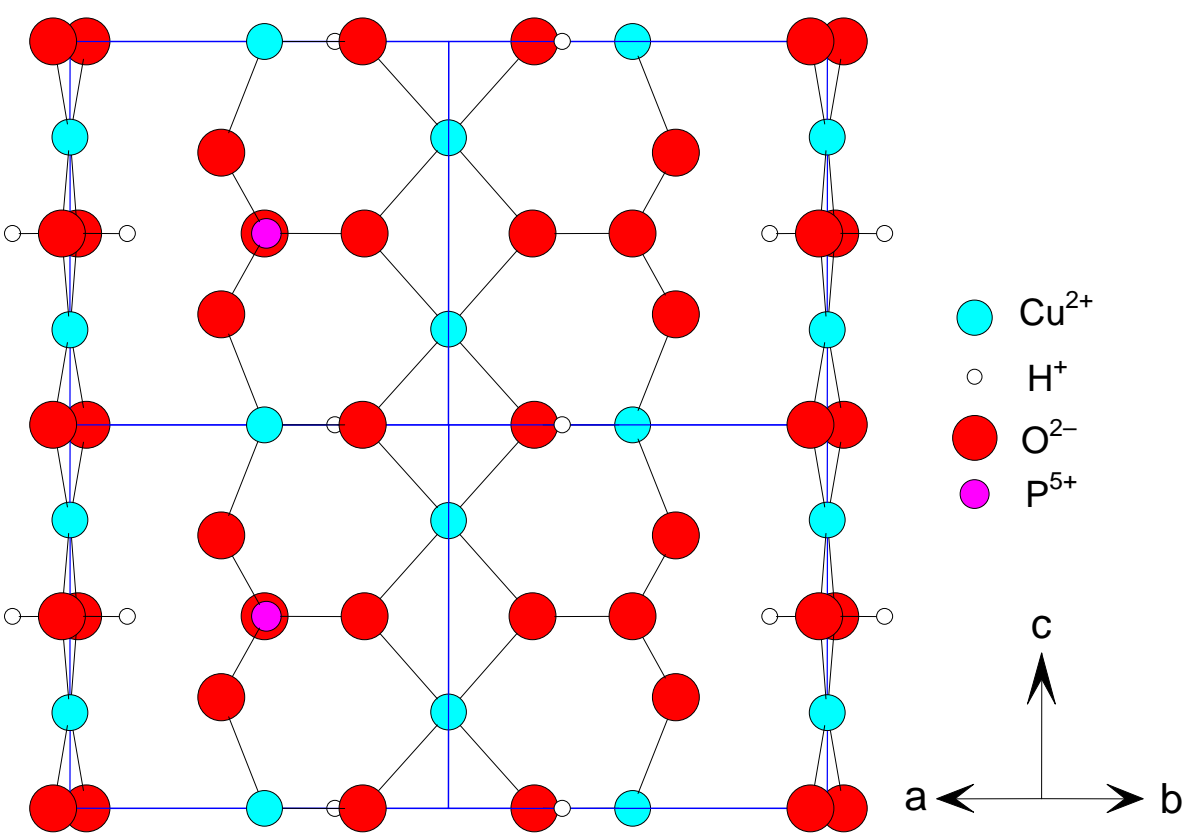

Figure S4. Copper hydroxyphosphate surface layer of $\{110\}$ cleavage planes. $\mathrm{Cu}-\mathrm{OH}$ bonds lie in (110) planes but between (001) planes. Blue lines represent the cell edge. 


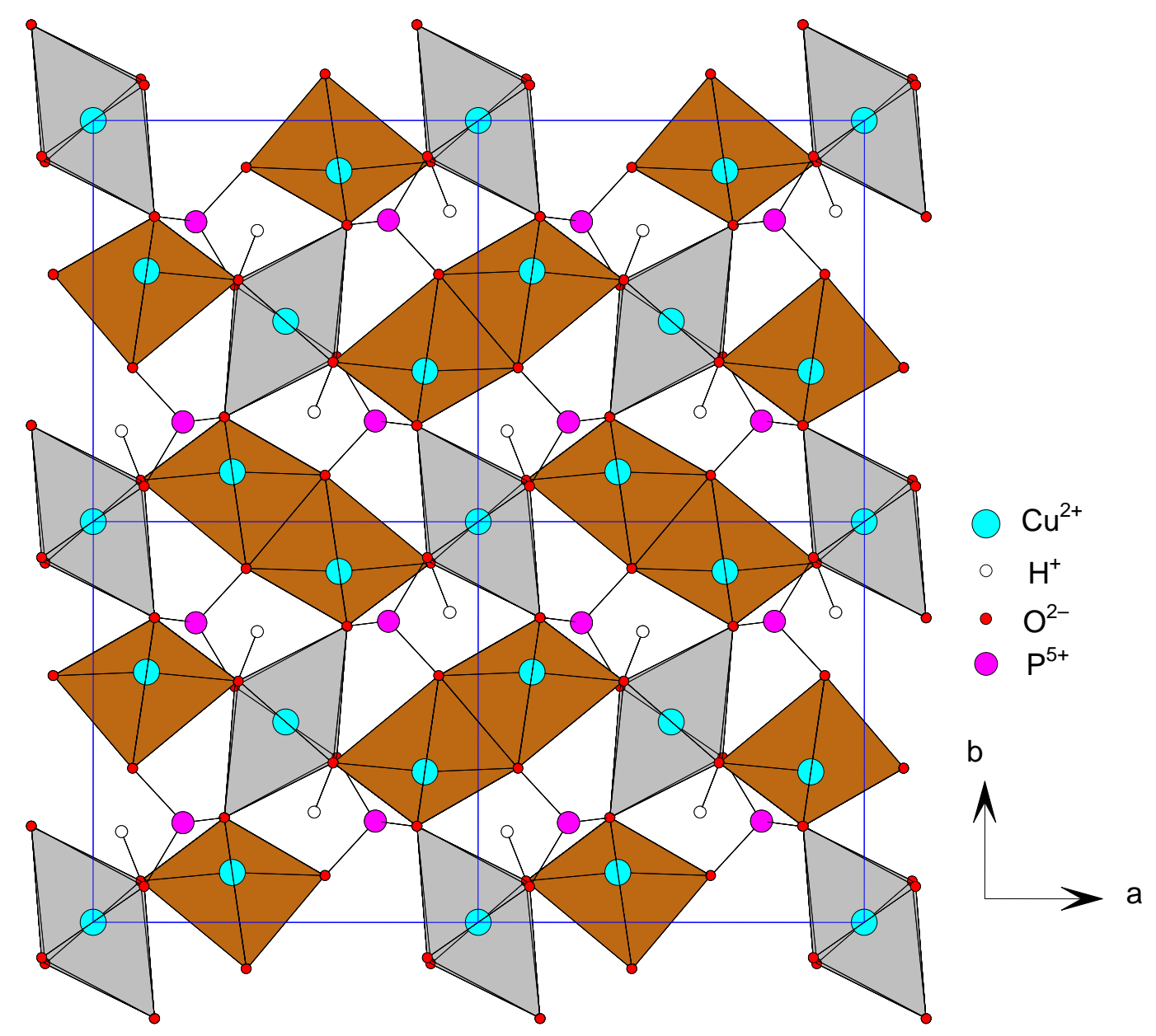

Figure S5. Projection of copper hydroxyphosphate structure along the $c$-axis, i.e., the (001) plane lies in the plane of the paper. Light-gray color: $\mathrm{CuO}_{4}(\mathrm{OH})_{2}$ octahedron, deep-brown color: $\mathrm{CuO}_{4}(\mathrm{OH})$ trigonal bipyramid. Blue lines represent the cell edge. 

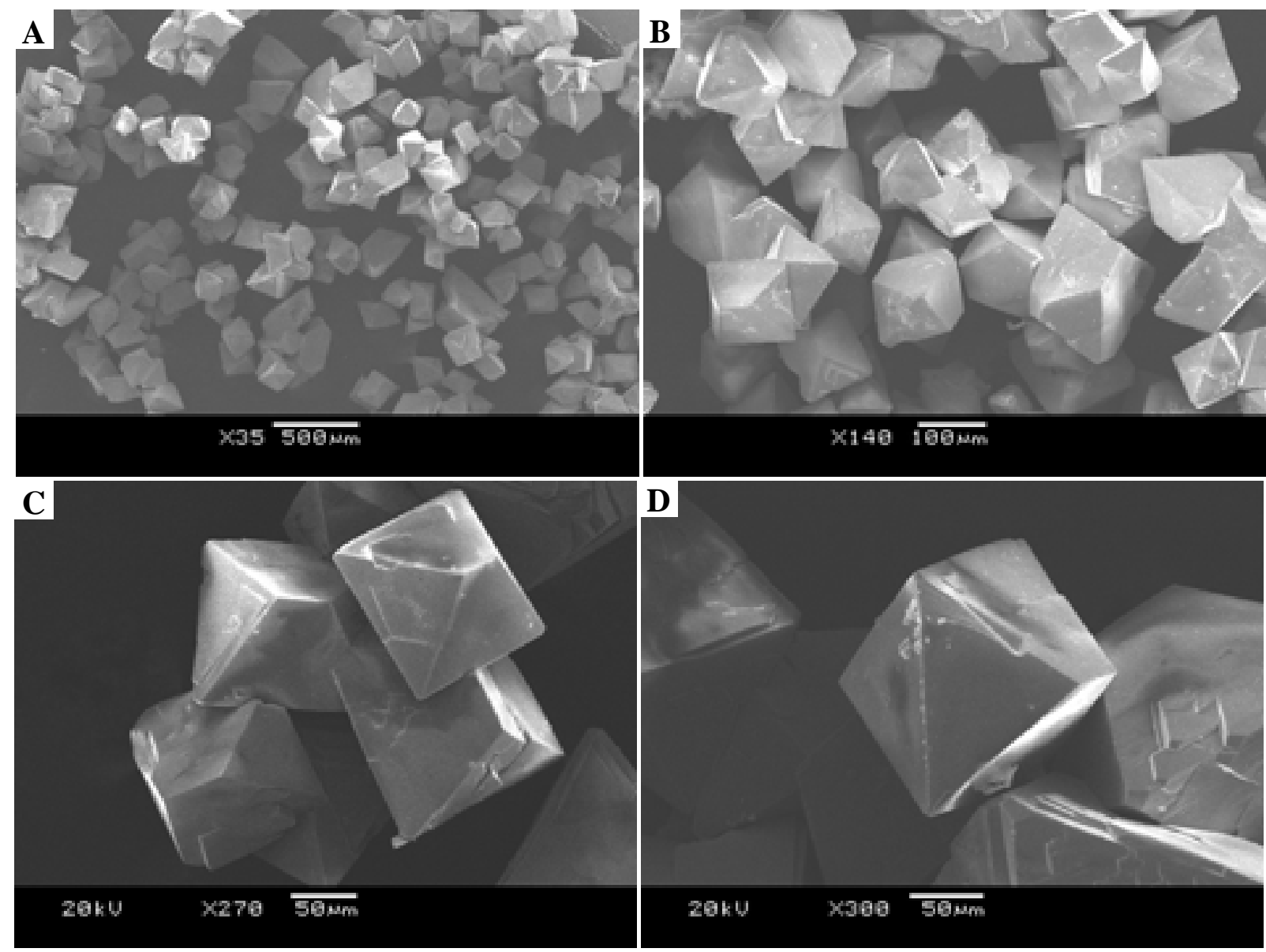

Figure S6. SEM images of typical copper hydroxyphosphate crystals (experimental conditions correspond to Figure 1, in the main text). (A and B) Overall product morphology; (C and D) Detailed views at different visual angles. 

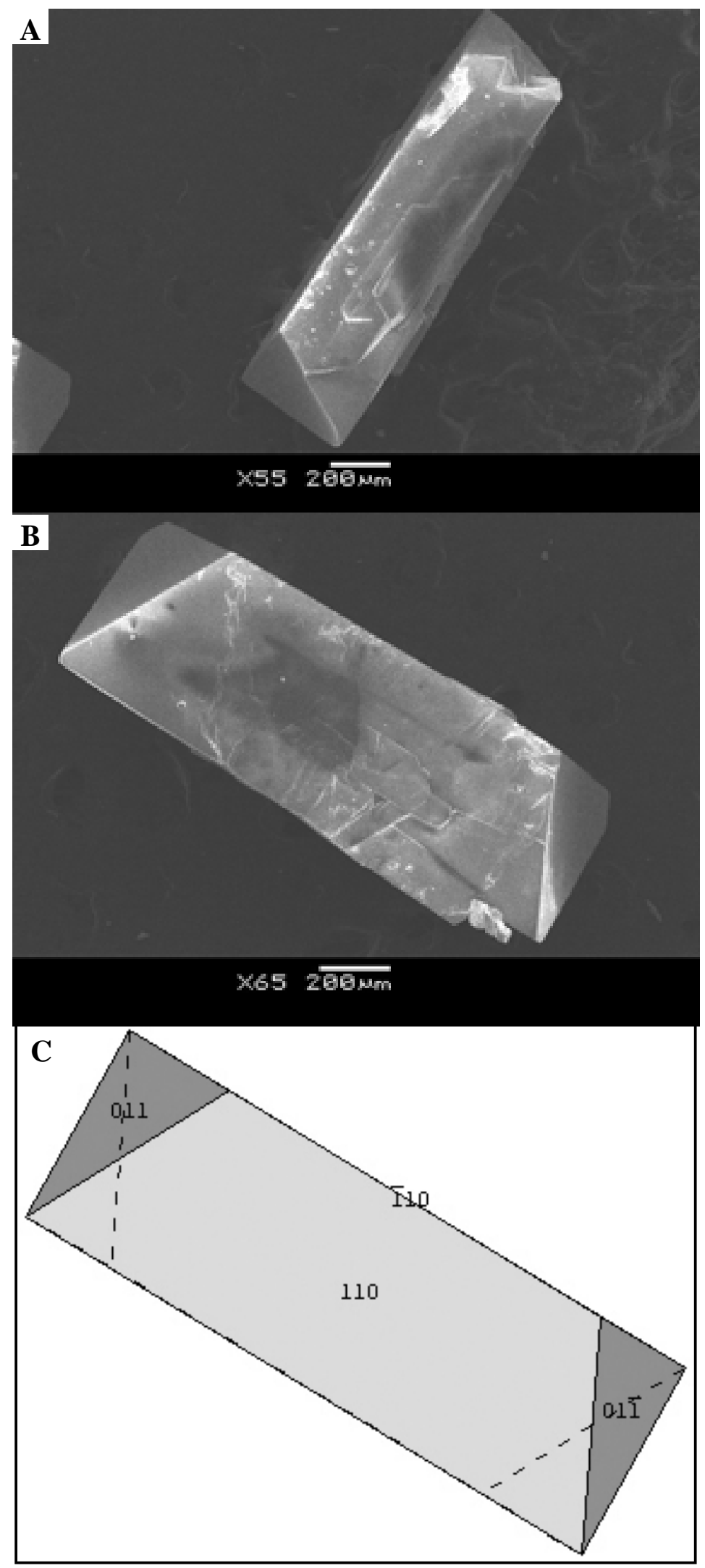

Figure S7. (A and B) SEM images of long copper hydroxyphosphate crystals (experimental conditions correspond to No 2 in Table 1). (C) A schematic illustration for the elongated octahedron with a high length-diameter ratio, which corresponds to (B). 

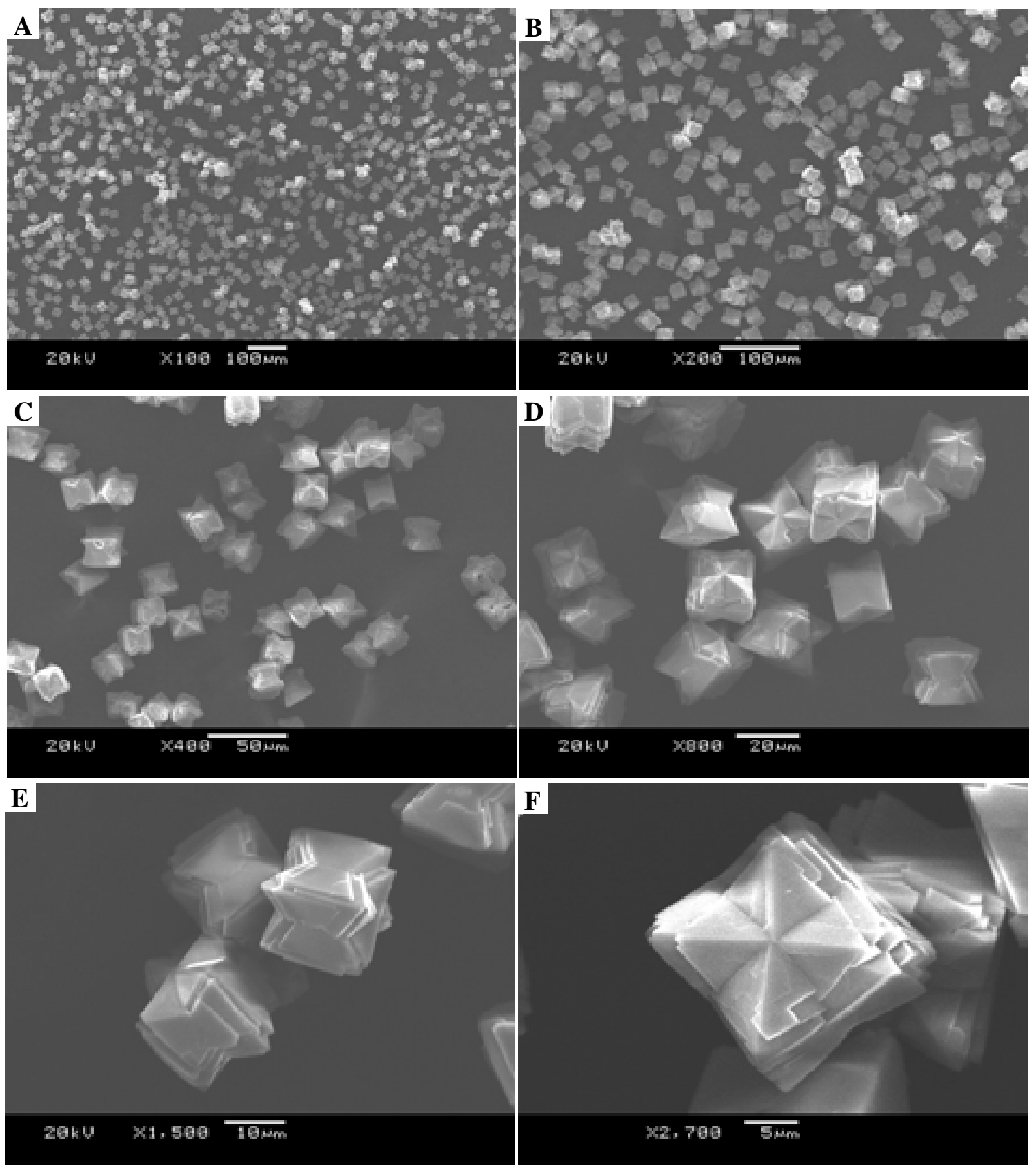

Figure S8. SEM images (experimental conditions correspond to Figure 3, in the main text) were taken with increasing magnifications (A-F). It is readily observed that copper hydroxyphosphate delicate cubes were obtained in large quantity and good uniformity by the current route. 


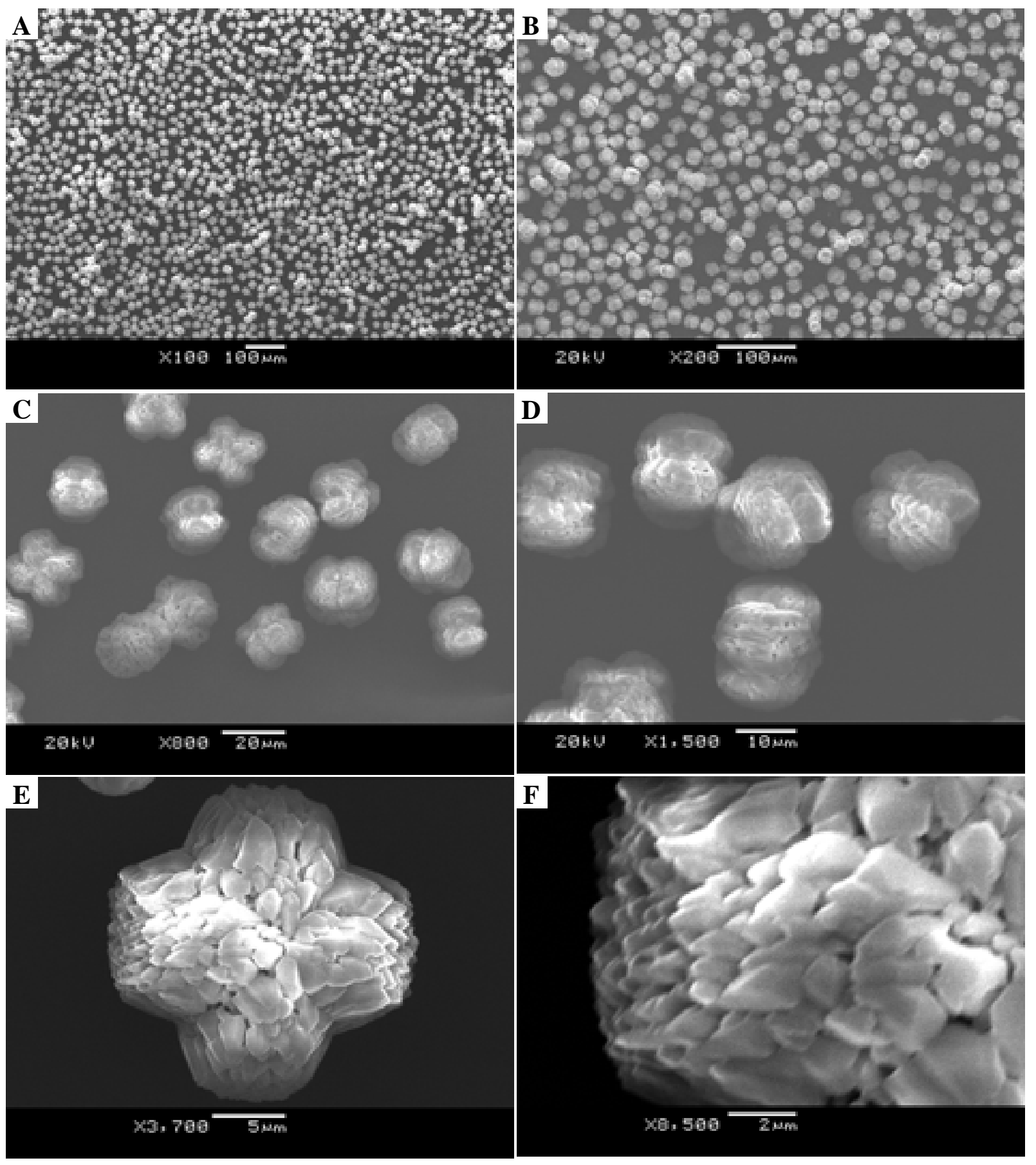

Figure S9. SEM images (experimental conditions correspond to Figure 5, in the main text) were taken with increasing magnifications (A-F). It is readily observed that copper hydroxyphosphate architectures were obtained in large quantity and good uniformity by the current route. 


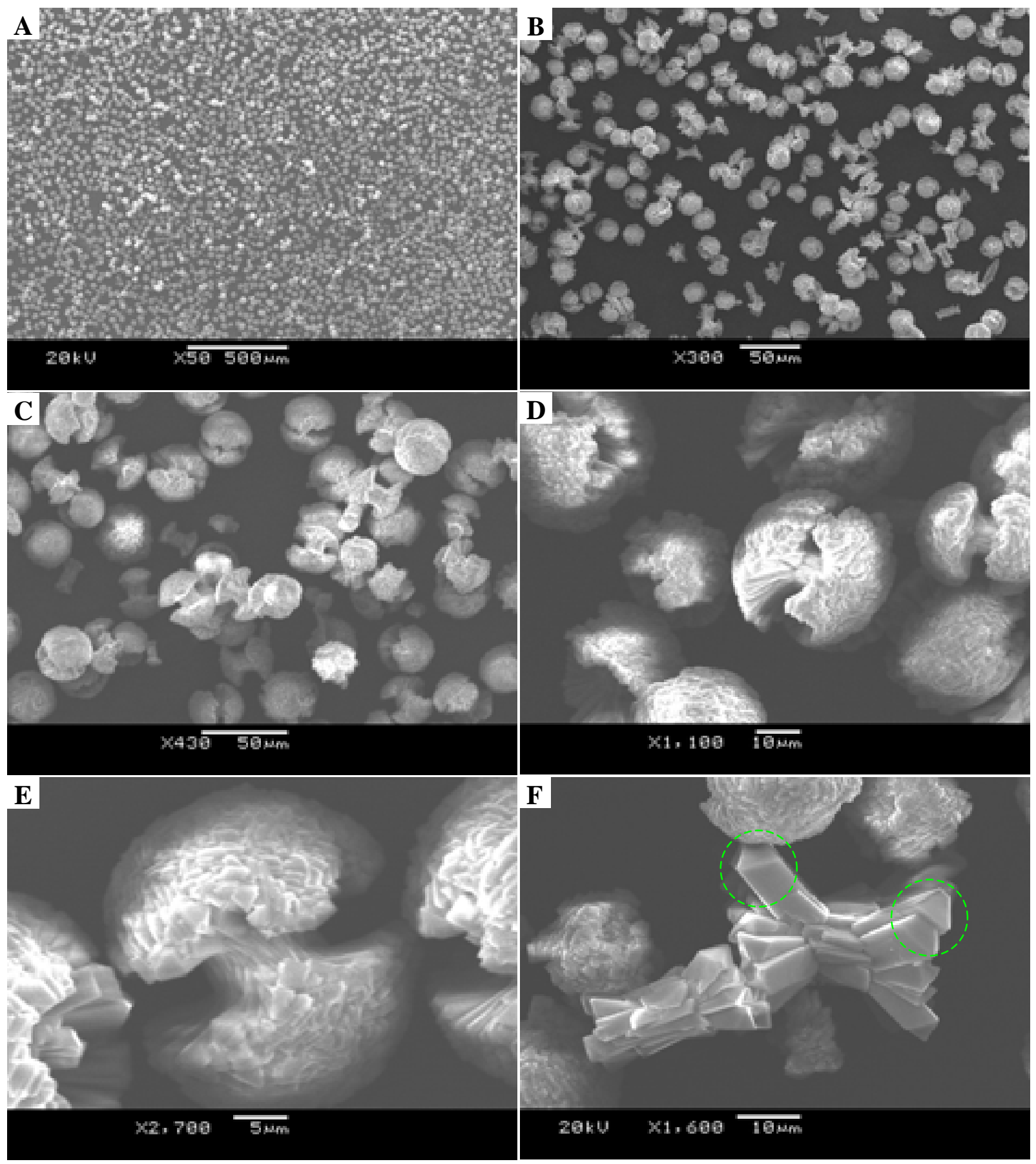

Figure S10. SEM images (experimental conditions correspond to Figure 6, in the main text) were taken with increasing magnifications (A-E). (F) The coexistence of different stages of aggregates, which show the characteristic of fractal objects: a self-similarity. As indicated by the dashed circles in green color, the piece of fractal object looks the same as the original one (the typical prism crystals shown in Figures 1 and S6). 
Parallel experiment: when $\left(\mathrm{NH}_{4}\right)_{2} \mathrm{HPO}_{4}$ was replaced by $\left(\mathrm{NH}_{4}\right) \mathrm{H}_{2} \mathrm{PO}_{4}$ (the molar ratio of $\mathrm{Cu}^{2+}$ and $\mathrm{PO}_{4}^{3-}$ was fixed as 2:1), we still can obtain the dumbbell-shaped architecture. In this architecture, it can be clearly seen that every piece of fractal objects looks the same as the original one.
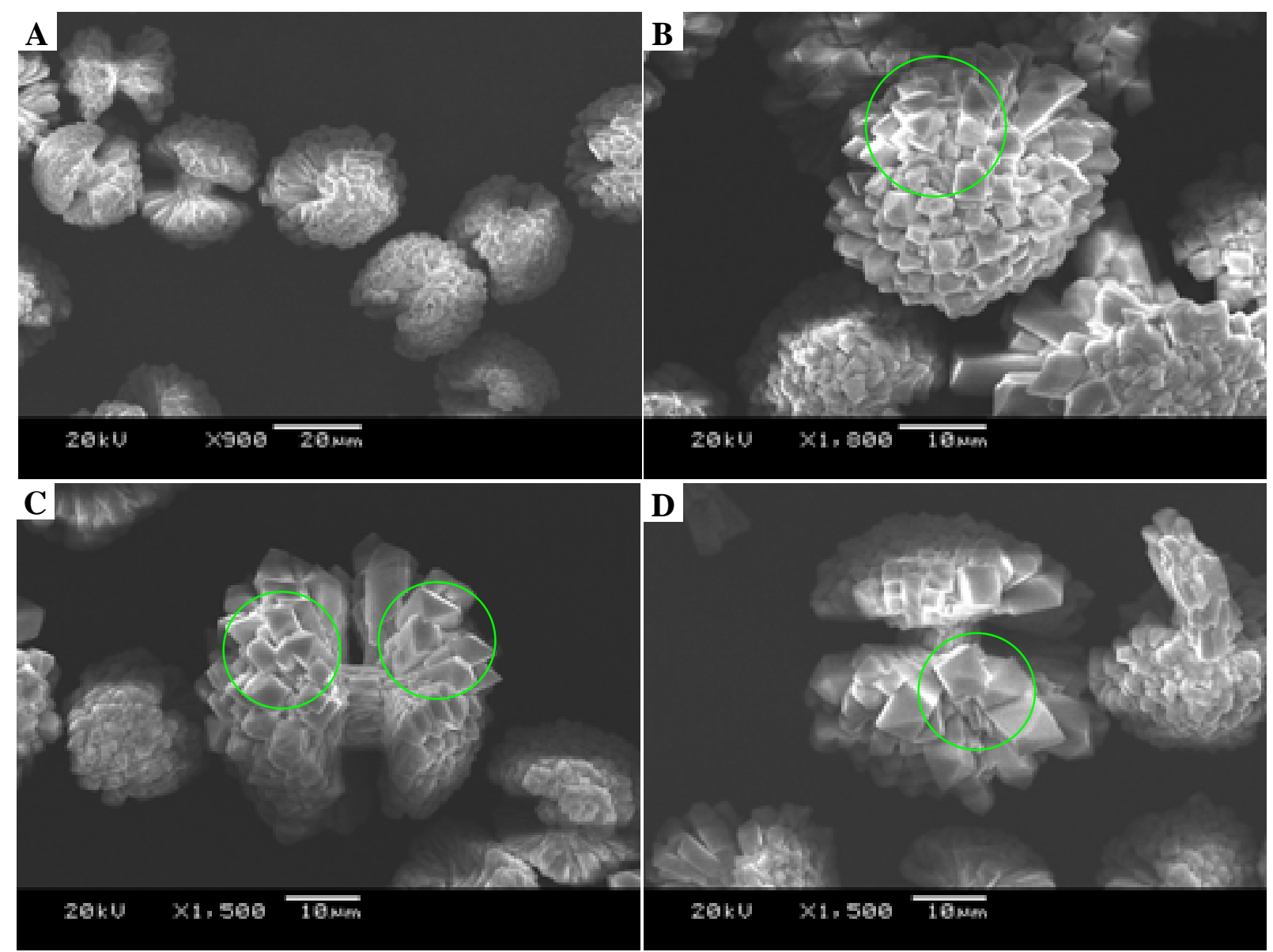

Figure S11. SEM images of dumbbell-shaped copper hydroxyphosphate architectures (experimental conditions: $20 \mathrm{~mL}$ of $\mathrm{CuAc}_{2}(0.25 \mathrm{M})+2.5 \mathrm{~mL}$ of $\left(\mathrm{NH}_{3}\right) \mathrm{H}_{2} \mathrm{PO}_{4}(1.0 \mathrm{M})$ at $180{ }^{\circ} \mathrm{C}$ for 48 h.). This architecture clearly shows the characteristic of fractal objects: a self-similarity. As indicated by the dashed circles in green color, each piece of fractal objects looks the same as the original one (the typical prism crystals have been shown in Figures 2 and S6). 


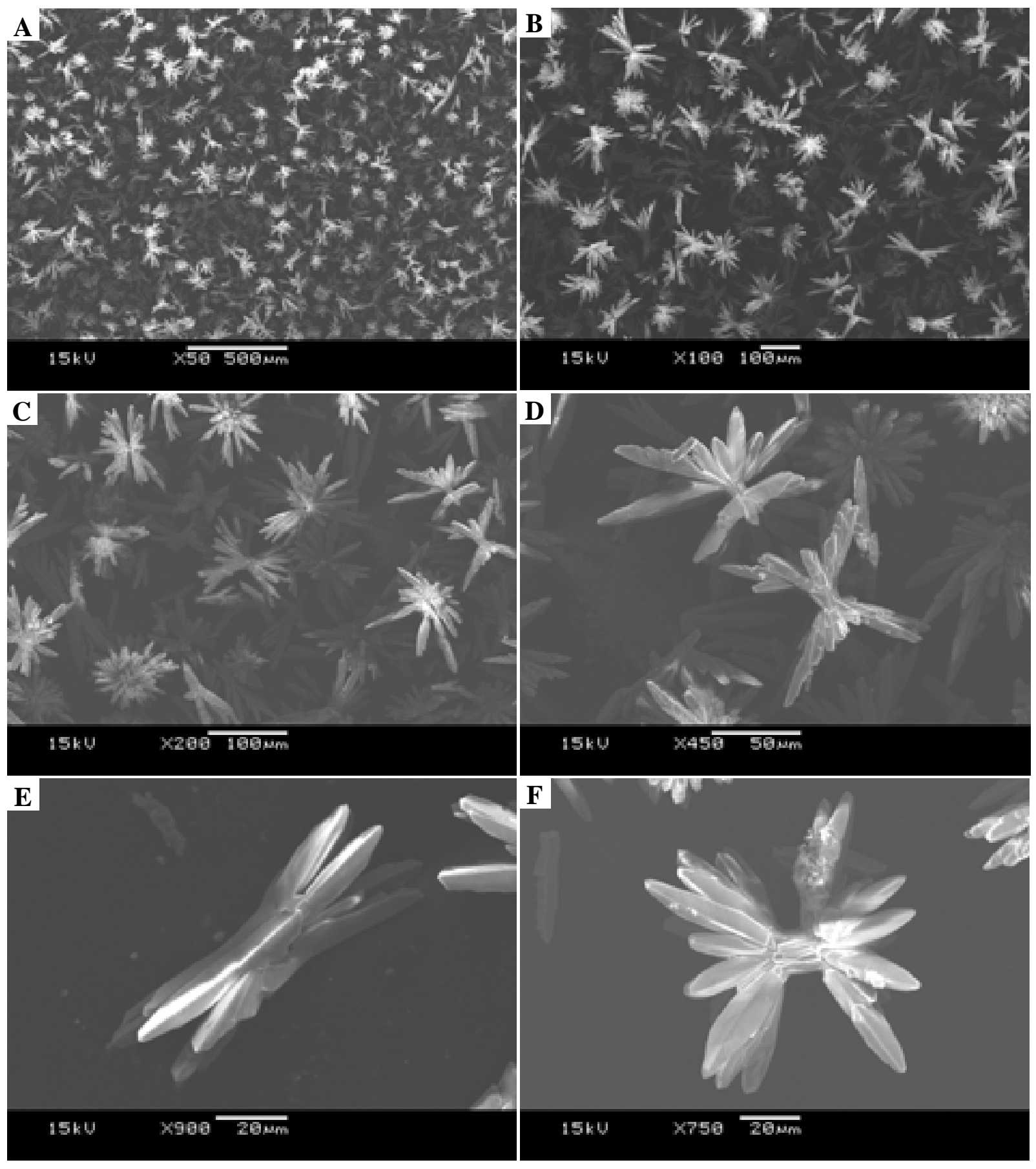



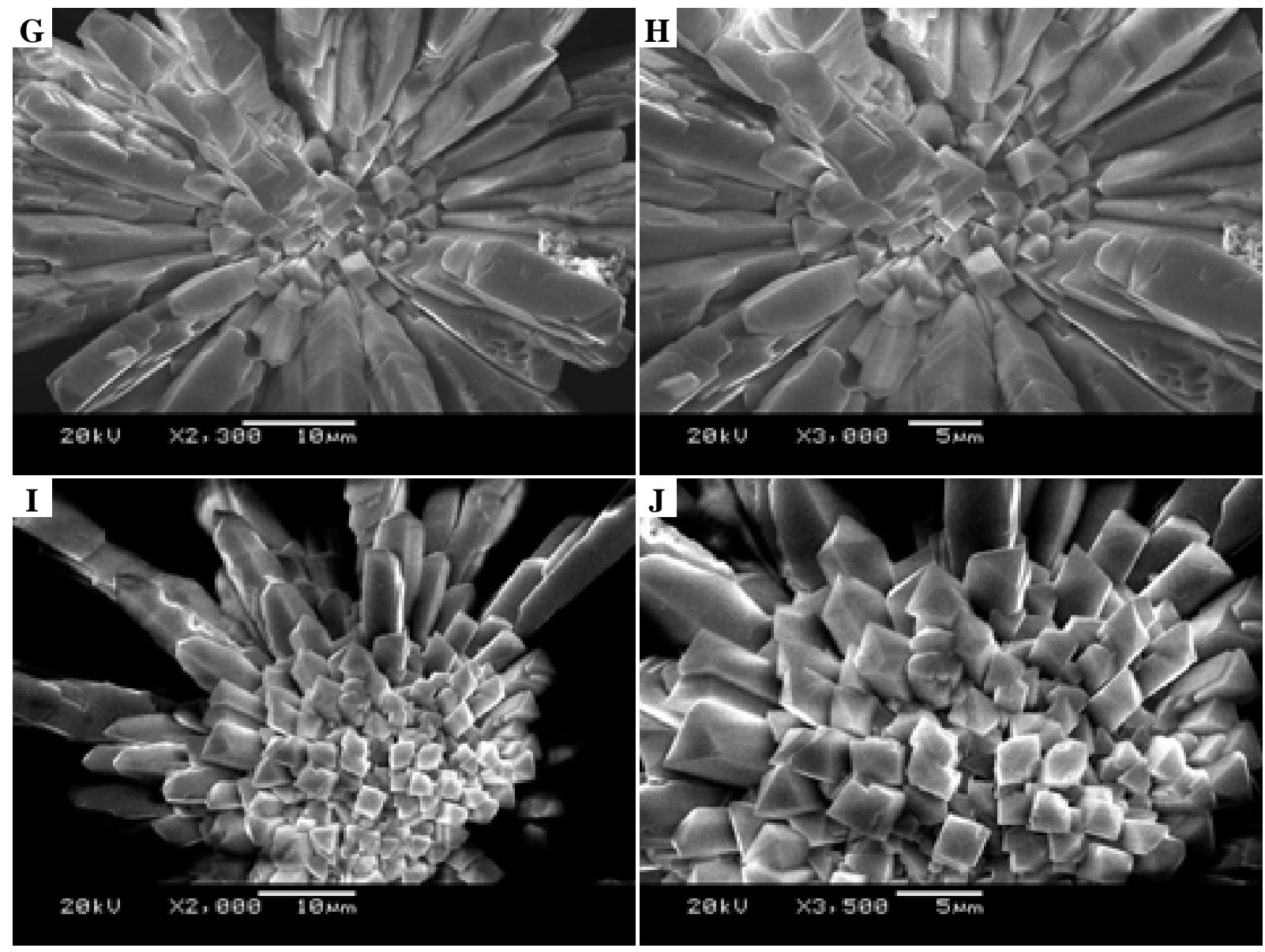

Figure S12. Flower-like copper hydroxyphosphate architectures. SEM images (experimental conditions correspond to Figure 7, in the main text) were taken with increasing magnifications (A-F). (G, H, I, and J) the clear view of the flower core, which shows the characteristic of fractal objects: a self-similarity. We can clearly see that each piece of fractal objects looks the same as the original one (the typical prism crystals have been shown in Figures 2 and S6). 

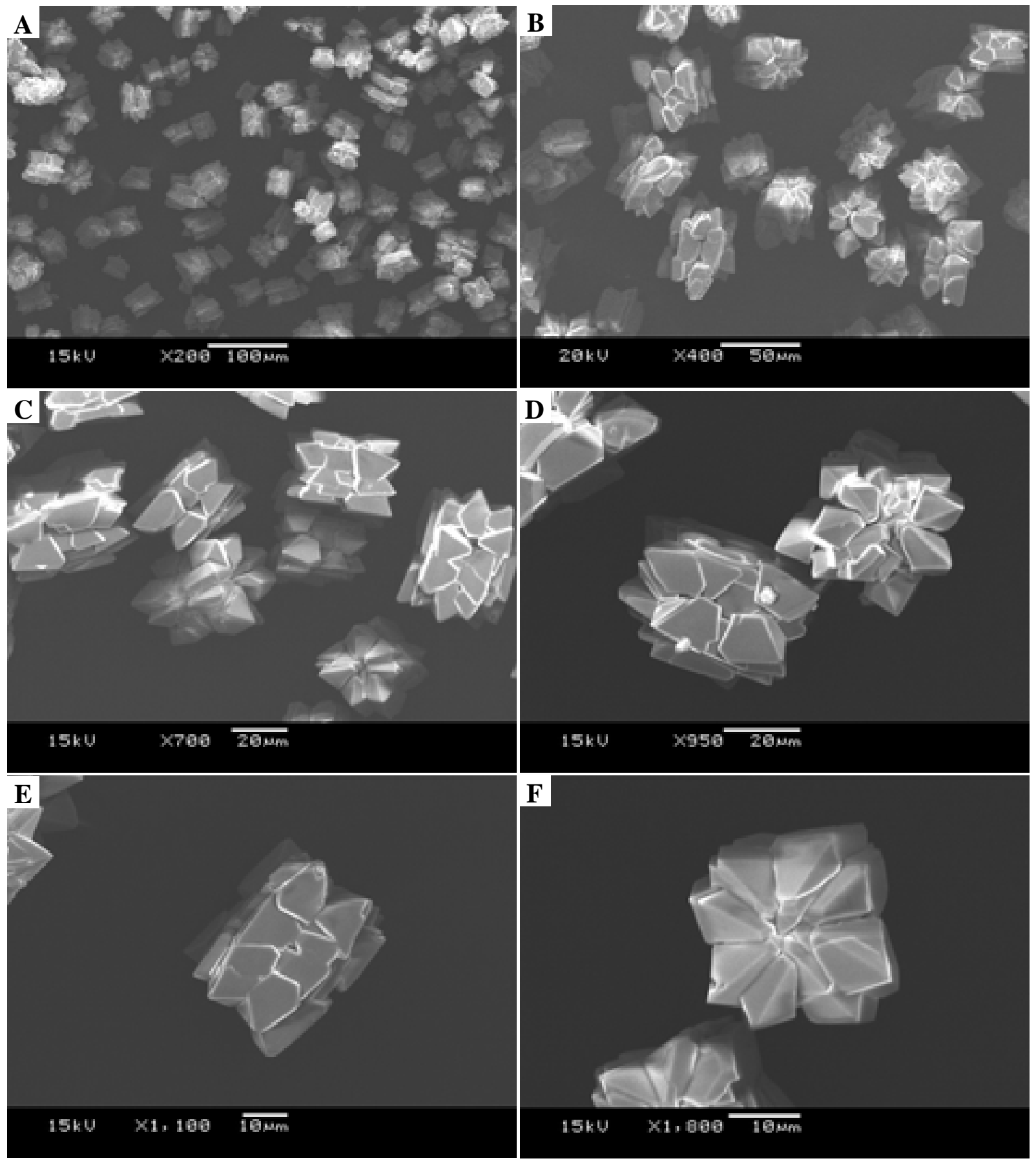

Figure S13. SEM images (experimental conditions correspond to Figure 8 in the main text) were taken with increasing magnifications (A-F). The morphology of the aggregates has a similarity with the rotation twinned-crystals based on the staking of typical copper hydroxyphosphate prismatic crystals, but this architecture is incompact, which is different from the architecture of rotation twinned-crystals (Figure 3). 


\section{Some parallel experimental results:}

(1) When the reaction was carried out at low temperature and short time, we can not obtain the copper hydroxyphosphate architectures but only copper phosphate hydrate $\left[\mathrm{Cu}_{3}\left(\mathrm{PO}_{4}\right)_{2} \cdot 3 \mathrm{H}_{2} \mathrm{O}\right]$, as shown in Figure S14. In this parallel experiment, we can deduce that the reagents react each other to form metastable copper phosphate hydrate $\left[\mathrm{Cu}_{3}\left(\mathrm{PO}_{4}\right)_{2} \cdot 3 \mathrm{H}_{2} \mathrm{O}\right]$ easily (at the beginning of the reaction), which then transfer to stable copper hydroxyphosphate crystals with the reaction proceeding.

(2) When $\left(\mathrm{NH}_{3}\right)_{2} \mathrm{HPO}_{4}$ was replaced by $\mathrm{K}_{2} \mathrm{HPO}_{4}$ (the molar ratio of $\mathrm{Cu}^{2+}$ and $\mathrm{PO}_{4}^{3-}$ was fixed as 1:2), we can not obtain the copper hydroxyphosphate architectures but the well-crystalline ludjibaite $\left[\mathrm{Cu}_{5}(\mathrm{OH})_{4}\left(\mathrm{PO}_{4}\right)_{2}\right]$ with an irregular aggregate, as shown in Figure S15. In this parallel experiment, we can clearly see the importance of the most stable square-planar amino complex

$\left[\mathrm{Cu}\left(\mathrm{NH}_{3}\right)_{4}^{2+}\right]$ in our present synthetic system. $\mathrm{Cu}^{2+}$ can be released gradually from the amino complex $\left[\mathrm{Cu}\left(\mathrm{NH}_{3}\right)_{4}^{2+}\right]$ during the crystallization process, which is also an essential factor for the formation of various complex architectures. 

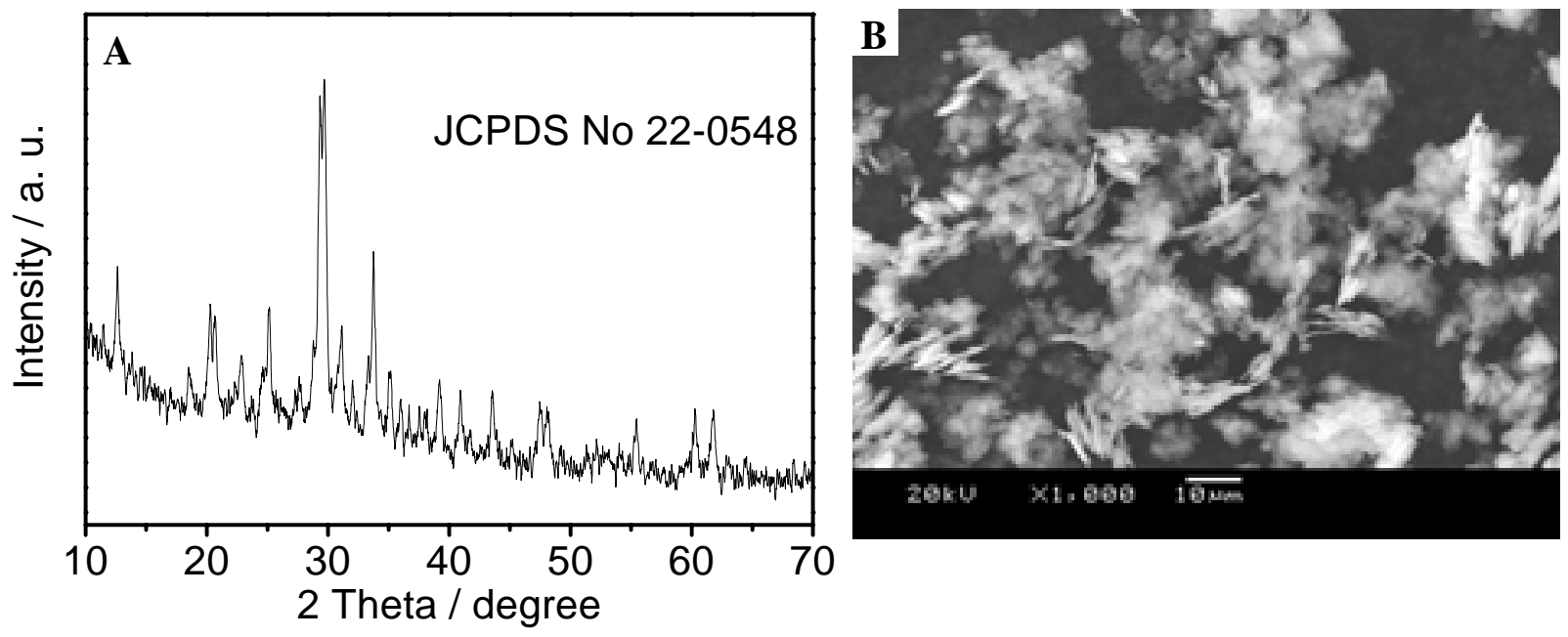

Figure S14. Copper phosphate hydrate $\left[\mathrm{Cu}_{3}\left(\mathrm{PO}_{4}\right)_{2} \cdot 3 \mathrm{H}_{2} \mathrm{O}\right]$, experimental conditions: $20 \mathrm{~mL}$ of $\mathrm{CuAc}_{2}(0.25 \mathrm{M})+10 \mathrm{~mL}$ of $\left(\mathrm{NH}_{4}\right)_{2} \mathrm{HPO}_{4}(1.0 \mathrm{M})$ at $110{ }^{\circ} \mathrm{C}$ for $6 \mathrm{~h}$. (A) XRD pattern of copper phosphate hydrate, JCPDS No 22-0548. (B) SEM image of copper phosphate hydrate, which shows an irregular morphology.
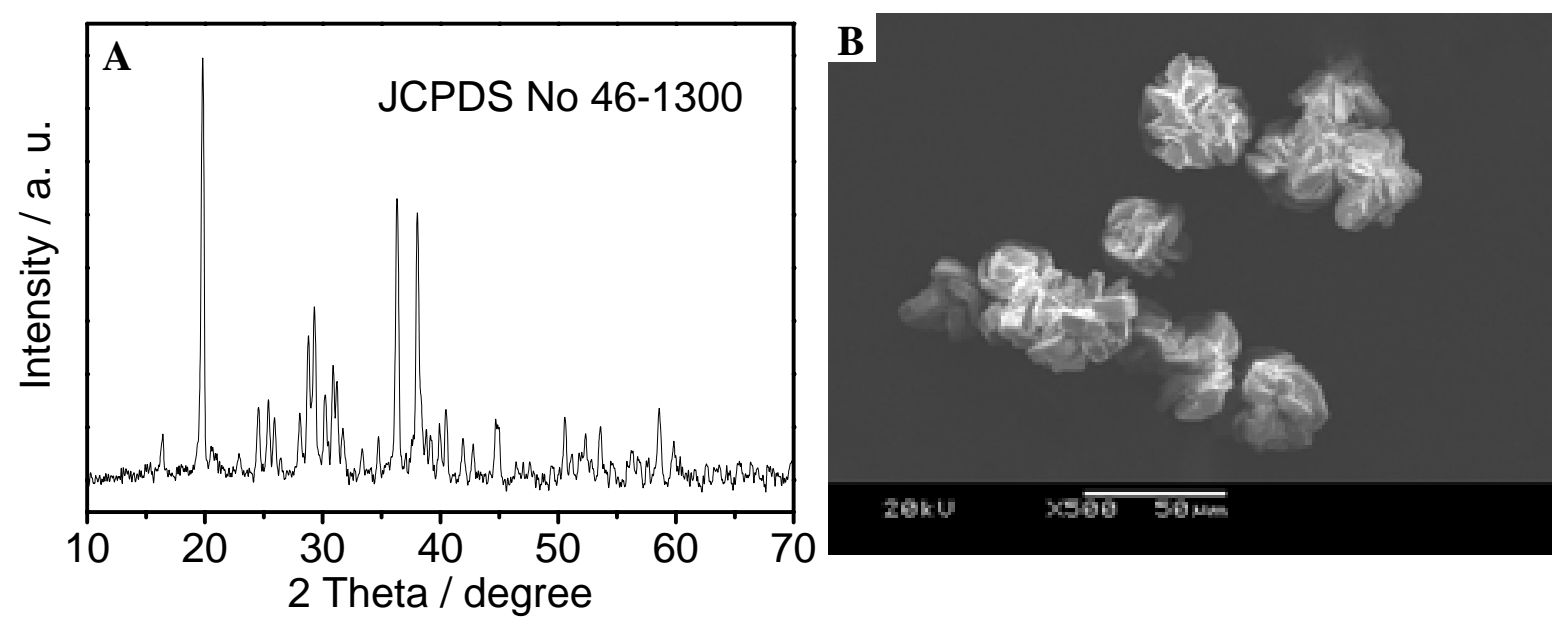

Figure S15. Ludjibaite $\left[\mathrm{Cu}_{5}(\mathrm{OH})_{4}\left(\mathrm{PO}_{4}\right)_{2}\right]$, experimental conditions: $20 \mathrm{~mL}$ of $\mathrm{CuAc}_{2}(0.25 \mathrm{M})+$ $10 \mathrm{~mL}$ of $\mathrm{K}_{2} \mathrm{HPO}_{4}(1.0 \mathrm{M})$ at $180{ }^{\circ} \mathrm{C}$ for $48 \mathrm{~h}$. (A) XRD pattern of Ludjibaite, JCPDS No 46-1300. (B) SEM image of Ludjibaite, which shows an irregular aggregate morphology. 